\title{
EDUCACIÓN
}

\section{Diseño universal de aprendizaje, una herramienta para la práctica inclusiva en el aula}

\author{
Violeta Rolón ${ }^{1}$
}

\begin{abstract}
Resumen
Introducción: La implementación del Diseño Universal de Aprendizaje ayuda a desarrollar las competencias que corresponden a cada ciclo de estudios, no se puede pretender que todos los alumnos aprendan lo mismo a la vez, de la misma manera y con los mismos métodos y recursos.

El camino hacia la implementación real de la educación inclusiva en las aulas siempre ha resultado complejo, pasando por diferentes dilemas cuya solución parece casi inalcanzable y vulnerando reiteradamente tratados y marcos de acción propuestos desde distintas organizaciones (García, 2011), no obstante, con la ley 5136/2013 y la reglamentación de la misma existe una mirada esperanzadora para los ANEAE.
\end{abstract}

Objetivo: Esta investigación se orientó a determinar el nivel de conocimiento sobre el DUA con el que cuentan los directivos y docentes de varias regiones educativas en la educación Escolar Básica y Media del Sistema Educativo Paraguayo.

Material y Método: Se optó por la realización de una encuesta, utilizando el formulario Google por ser una herramienta simple y fácil de utilizar tanto para quien lo redacta como para quien debe responder. El cuestionario se elaboró utilizando preguntas abiertas y preguntas cerradas; El cuestionario se distribuyó en 10 ítems. Las variables que se consideraron son: conocimiento sobre el DUA, utilización del DUA, interés en conocer sobre el DUA.

El Formulario fue enviado a los directores y docentes de los distritos de Capiatá, Isla Pucú y Nueva Colombia. El 100\% de la población lo constituyeron 81 personas y la muestra fue del $40,5 \%$, es decir, fueron 50 personas encuestadas. Resultados: Se presenta como dato importante que, el 97,7\% de directivos y docentes afirmaron que el diseño Universal de Aprendizaje representa un reto para afrontar las necesidades específicas de aprendizaje; que el DUA sugiere el uso material de instrucción flexibles y que, sin dudas, faltará más capacitación sobre el tema para poder enseñar, brindando la oportunidad a los alumnos con necesidades especiales de aprender desde la diversidad. El 100\% respondió que necesitan ser capacitados sobre el tema; que ellos suelen escuchar sobre el tema, pero que hasta hoy día no han utilizado el DUA. Expresaron que la

\footnotetext{
1. Universidad Nacional de Asunción, Facultad de Filosofía.

E-mail: viorolon@gmail.com

DOI: 10.26885/rcei.foro.2018.82
} 
encuesta les fue de utilidad para verificar que necesitan investigar más sobre las bondades de este tipo de planeamiento. DUA significa un nuevo marco para el currículum que permite realizar mejoras en el acceso a la educación por parte de todos los estudiantes, especialmente los estudiantes con discapacidad. Para la implementación del DUA debe considerarse la puesta en práctica de cada principio con sus pautas y puntos de verificación, las pautas no pretenden ser una receta de pasos a seguir, al igual que el diseño universal, deben ser mezcladas y ajustadas para adecuarse al currículo, todos los componentes del currículo (metas, métodos, materiales o evaluaciones) son diseñados para tratar de satisfacer las necesidades individuales de los alumnos.

Conclusiones: Los resultados de la investigación demuestran una necesidad preponderante de conocer el Diseño Universal de Aprendizajes, y para afrontar esta problemática es necesario desarrollar varios encuentros de círculos de aprendizajes y talleres donde se desarrollen temas relevantes sobre el DUA, con materiales de fácil comprensión, aplicación y desarrollo, al mismo tiempo es de fundamental importancia generar espacios activos a fin de captar el interés sobre el abordaje del tema.

Palabras clave: educación inclusiva, diseño, aprendizaje.

\section{RefERENCIAS}

Alba, C., \&Zubillaga, A. (2012). De la accesibilidad de las tecnologías a la educación accesible: Aportaciones del Diseño Universal para el aprendizaje. Actas de las VIII Jornadas Científicas Internacionales de Investigación sobre Discapacidad. Salamanca: INICO,Salamanca.

Ainscow, M. (2002). Rutas para el desarrollo de prácticas inclusivas en los Sistemas Educativos. Revista de Educación, 327, 69-82

Arnaiz, P (2003). Educación inclusiva: una escuela para todos. Archidona (Málaga): Aljibe.

Bars, I. S., Fuentes, S. S., Giné, C. G., \& Villoria, E. D. (2014). Análisis de los distintos enfoques del paradigma del diseño universal aplicado a la educación. Revista latinoamericana de educación inclusiva, 8(1), 143-152.

Duck, C. (2012). Una evaluación inclusiva para una educación inclusiva. Revista Latinoamericana de Educación Inclusiva, 6(1), pp. 11-13. 